\title{
EFFECT OF COVER CONCRETE ON ANTI-BUCKLING OF LONGITUDINAL BARS IN REINFORCED CONCRETE COLUMNS
}

\author{
Jun-ichi HOSHIKUMA ${ }^{1}$, Shigeki $\mathrm{UNJOH}^{2}$ and Akihiko SHIOJIMA ${ }^{3}$ \\ ${ }^{1}$ Deputy Division Head, Construction Planning Division, Policy Bureau, \\ Ministry of Land, Infrastructure and Transport \\ (2-1-13 Kasumigaseki, Chiyoda-ku, Tokyo, 100-1918) \\ E-mail: hoshikuma-j2u8@mlit.go.jp \\ ${ }^{2}$ Team Leader, Earthquake Engineering Research Team, Earthquake Disaster Prevention Research Group, \\ Public Works Research Institute \\ (1-6, Minamihara, Tsukuba City, Ibaraki, 305-8516) \\ E-mail: unjoh@pwri.go.jp \\ ${ }^{3}$ Researcher, Earthquake Engineering Research Team, Earthquake Disaster Prevention Research Group, \\ Public Works Research Institute \\ (1-6, Minamihara, Tsukuba City, Ibaraki Prefecture, 305-8516) \\ E-mail; siojima@pwri.go.jp
}

\begin{abstract}
This paper proposes an analysis model that, based on fiber element analysis, appropriately evaluates the phenomenon - spalling of cover concrete by buckling of longitudinal bars under the mechanism of the formation of a plastic hinge in a reinforced concrete bridge column under cyclic loading - and presents a study of its suitability based on a comparison with cyclic loading testing of reinforced concrete bridge column models performed by the authors in the past. The results have revealed that by modeling the cover concrete as a beam with its thickness treated as effective height and considering controlling the force of the longitudinal bars pushing outwards based on the bending resistance of this beam, it is possible to estimate the deformation of the bridge column when the longitudinal bars buckle causing spalling of the cover concrete with relative accuracy.
\end{abstract}

Key Words: RC columns, anti-buckling, cover concrete, fiber element analysis, seismic evaluation

\section{INTRODUCTION}

Seismic design of important bridges for level 2 earthquake ground motion includes verification that damage to parts that become plastic hinges will be a degree of damage that can be easily repaired ${ }^{1)}$. The specific image of damage to an RC bridge column that can be easily repaired differs according to the location conditions of the bridge column, but generally it is assumed that the easiness of repair varies greatly according to whether or not the longitudinal bars buckled. Therefore, when performing seismic design, it is important to appropriately evaluate how many cycles of plastic deformation of a bridge column will cause buckling of the longitudinal bars.

But the phenomenon that causes longitudinal bars to start buckling is extremely complex and very difficult to analytically evaluate, so the method that is generally used is to estimate the displacement of the bridge columns when the longitudinal bars start to buckle using an empirical equation based on the results of cyclic loading testing ${ }^{1), 2), 3)}$.

So this study used fiber element analysis that is a general purpose analysis method, to study an analysis model capable of representing the pushing out of cover concrete by longitudinal bars as they buckle, and it verified its applicability by comparison with the results of a past cyclic loading test. 
2. PAST RESEARCHES ON THE ASSESSMENT OF THE BUCKLING OF LONGITUDINAL BARS

A number of methods of assessing when longitudinal bars will buckle in RC bridge columns under cyclic loading have been proposed.

Suda, Murayama et al. have shown that buckling occurs when compressive force acts on longitudinal bars with a certain radius of curvature, the force pushes the cover concrete outwards, and when the splitting stress that this force generates exceeds the splitting strength of the concrete considering the action of cyclic loading ${ }^{4}$. The force that pushes the cover concrete outwards is obtained by the equation (1) based on Fig.1.

$$
H=2 F \sin \theta \approx 2 F \theta
$$

where,

$H$ : force of the longitudinal bars pushing out the cover concrete

$F$ : compressive force generated in the longitudinal bars

$\theta$. angle of the longitudinal line of the longitudinal bars to the vertical axis

If the average radius of curvature of the longitudinal bars in the section with length $L$ is represented by $\phi$, the force that pushes the cover concrete outwards is obtained by the equation (2).

$$
H=F \phi L
$$

Shima et al. evaluated the force of the longitudinal bars pushing out the cover concrete by basically the same method as Murayama et. al, but they proposed evaluating the force resisting buckling by separating the resistance of the cover concrete and the resistance of the hoop ties, and evaluating the properties of the resistance of the cover concrete based on the results of a pull-out test of all the reinforcing bars installed inside the concrete ${ }^{5)}$.

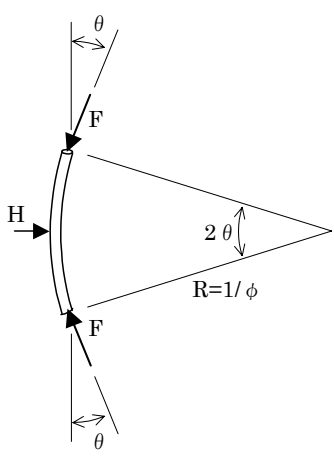

Fig.1 Bending of the reinforcing bars and force pushing them out
Maekawa et al. proposed an analysis method that assumes that when the compressive strain generated in the cover concrete exceeds a critical value, it spalls and the longitudinal bars buckle, and they provided a method of quantitatively calculating this limit strain ${ }^{6}$.

\section{FIBER ELEMENT ANALYSIS OF PAST TESTS AND EVALUATION OF THE BUCKLING CONTROL EFFECTS OF LONGITUDINAL BARS}

\section{(1) Test specimens analyzed and the outline of the experimental results}

Three test specimens were analyzed: full-size L specimen with section dimensions of $2,400 \mathrm{~mm}$ that the authors conducted separately ${ }^{7)}$, S0 specimen with section dimension of $600 \mathrm{~mm}^{8}$, and S1 specimen in which longitudinal bars were installed in 2 layers to increase the buckling control effects of the longitudinal bars ${ }^{8)}$. Fig.2 shows the section specifications of these specimens. In the S1 specimen, approximately $2 / 3$ of the total longitudinal bars were deliberately installed inside the section in order to increase the buckling control effects of the longitudinal bars by guaranteeing that the cover concrete is thick.

See the source documents for the detailed experimental results ${ }^{7), 8}$, but the results of cyclic loading testing of these test specimens show that the spalling of the cover concrete accompanying the buckling of the longitudinal bars that is the focus of this study occurred during the $4 \delta_{\mathrm{y}}$ loading, the $6 \delta_{\mathrm{y}}$ loading, and the $8 \delta_{\mathrm{y}}$ loading in the case of the $\mathrm{L}$ specimen, S0 specimen and S1 specimen respectively. In the S1 specimen, the plastic deformation performance was improved simply by installing longitudinal bars in two layers, so verification was done to find out if effects of this kind can be represented by an existing evaluation method.

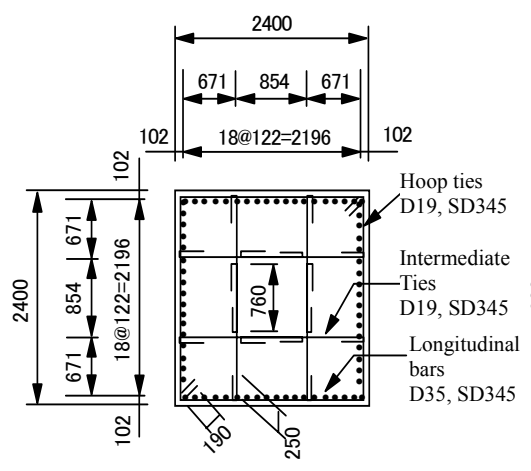

(a)L specimen

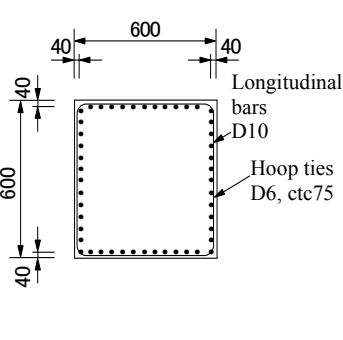

(b)S0 specimen

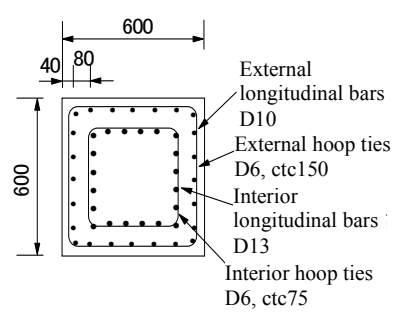

(c)S1 specimen

Fig.2 Section of the test specimens tested 


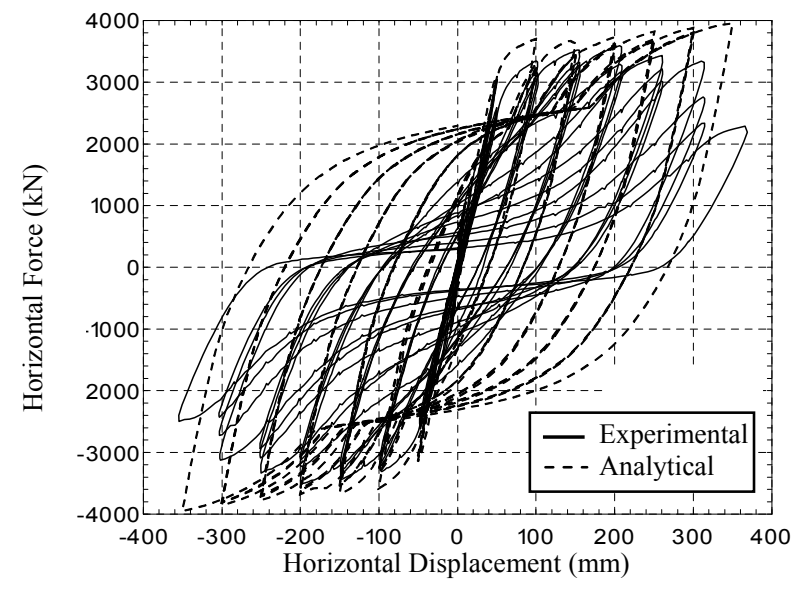

(a) L specimen

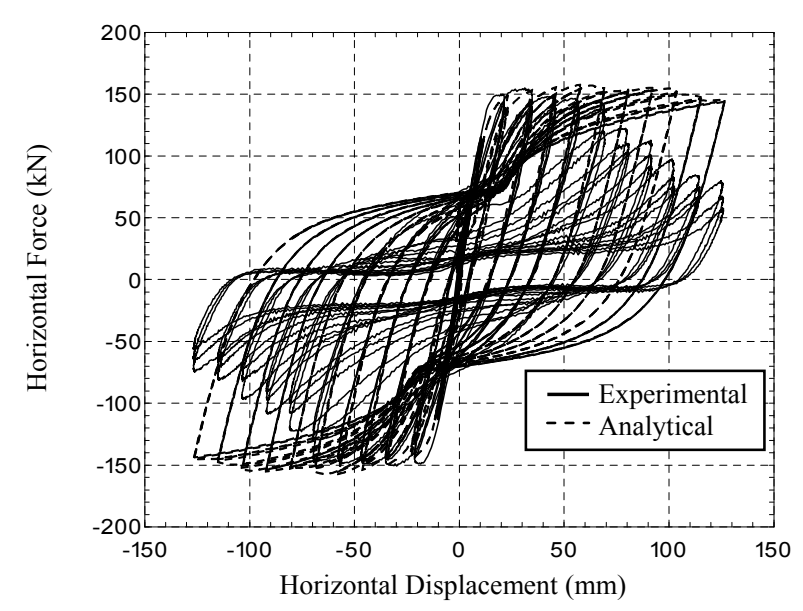

(b) S0 specimen

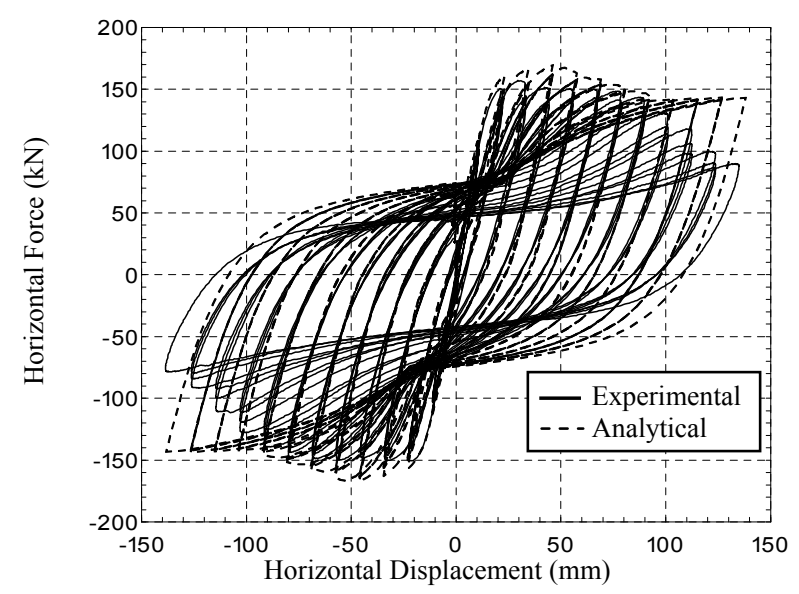

Fig.3 Comparison with experimental and analytical results

\section{(2) Analysis method and analysis model}

The analysis was done based on the fiber element analysis method. The fiber element analysis method is often used to analyze RC structures because of its general purpose characteristics: it can be applied to members with optional section shapes and it can be applied to study behavior in cases where the acting axial force fluctuates. But when it is used to evaluate the plastic deformation performance of an $\mathrm{RC}$ bridge column, the results of the analysis vary, particularly according to the way that the element division height in the member axis direction is set. For this study, it was assumed that it was appropriate to define the element division height as the height of the damage that actually occurs when longitudinal bars buckle, considering the impact of the element division and the localization of strain. So the plastic hinge length evaluation equation proposed by Asazu et al. ${ }^{9)}$ was applied based on buckling analysis of longitudinal bars, and the plastic hinge length calculated in this way was considered to be the element division length. According to the hinge length evaluation equation of Asazu et al., if the plastic hinge length is calculated for the test specimens that were analyzed considering the buckling control effects of hoop ties and intermediate ties, it is $873 \mathrm{~mm}$ $(0.36 D, D$ : section dimension) for the $\mathrm{L}$ specimen, and $383 \mathrm{~mm}(0.64 D)$ for the $\mathrm{S} 0$ and $\mathrm{S} 1$ specimens.

As the stress-strain curve of the concrete, a model that accounts for confining effects proposed by Hoshikuma et al. ${ }^{10)}$ was applied as the skeleton curve, and the revised Muguruma model ${ }^{11)}$ was applied as the hysteresis model for unloading and reloading. But the cover concrete was modeled without considering confining effects.

As the stress-strain curve of the reinforcing bars, the Menegotto-Pinto model that considers the Bauschinger effect $^{12)}$ was applied. The Menegotto-Pinto model cannot reproduce behavior after buckling of reinforcing bars, but because this study was focused on the deformation of a bridge column at the time that buckling of longitudinal bars starts, behavior after buckling was not studied.

The analysis was done by gradually increasing or gradually reducing the displacement at the point that was the loading point during the test. The increase/decrease of displacement in each step of the analysis was assumed to be $1 / 350$ of the total displacement of three cycles of loading for each loading step.

And the material property values of the concrete and of the reinforcing bars used for the analysis were all actual values obtained by material tests.

\section{(3) Comparison with experimental and analyti- cal results and assessment of the buckling period}

Fig.3 shows the results of comparing the horizontal force-horizontal displacement hysteresis curves obtained by the above analysis method with actual material properties. It reveals that the experimental and analytical values for the behavior until just before the longitudinal bars buckled conformed closely for all specimens. And of course, because the impact of the buckling on the 


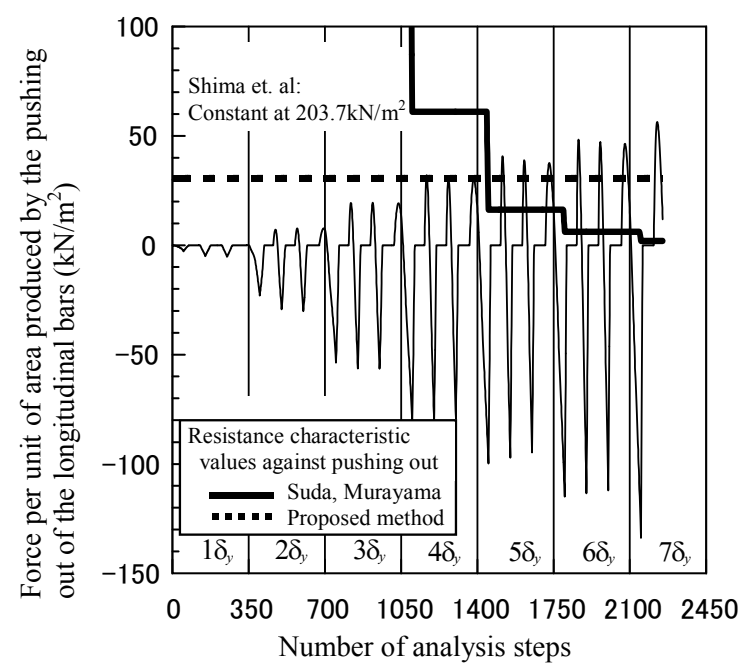

(a) Judgement based on push-out force

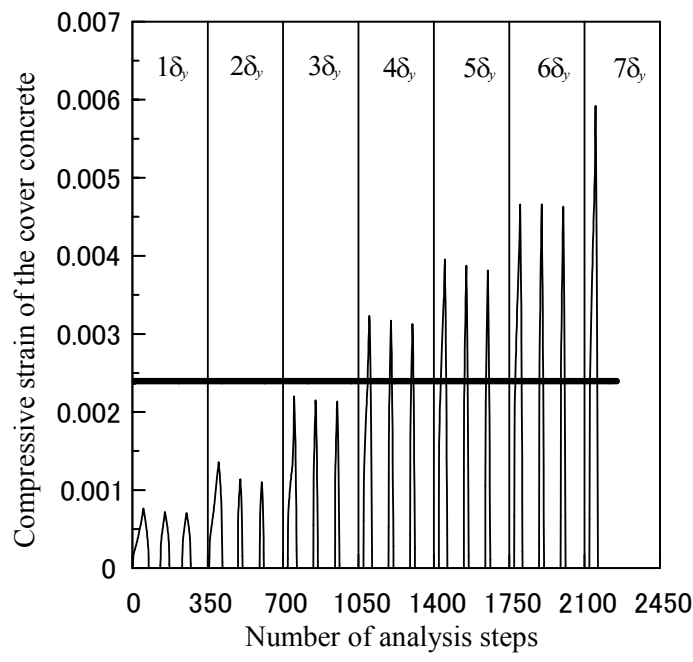

(b) Judgement by compressive strain (Maekawa)

Fig.4 Buckling judgement of longitudinal bars for the L specimen

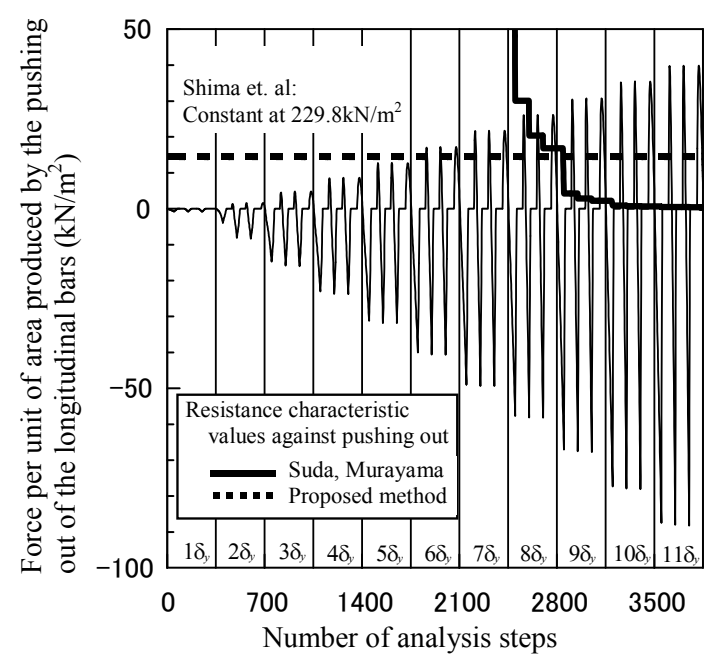

(a) Judgement based on push-out force

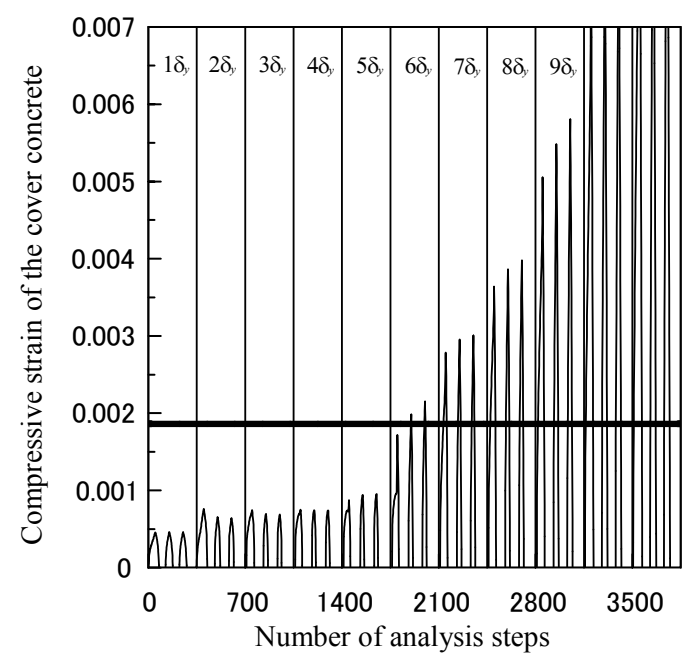

(b) Judgement by compressive strain (Maekawa)

Fig.5 Buckling judgement of longitudinal bars for the S0 specimen

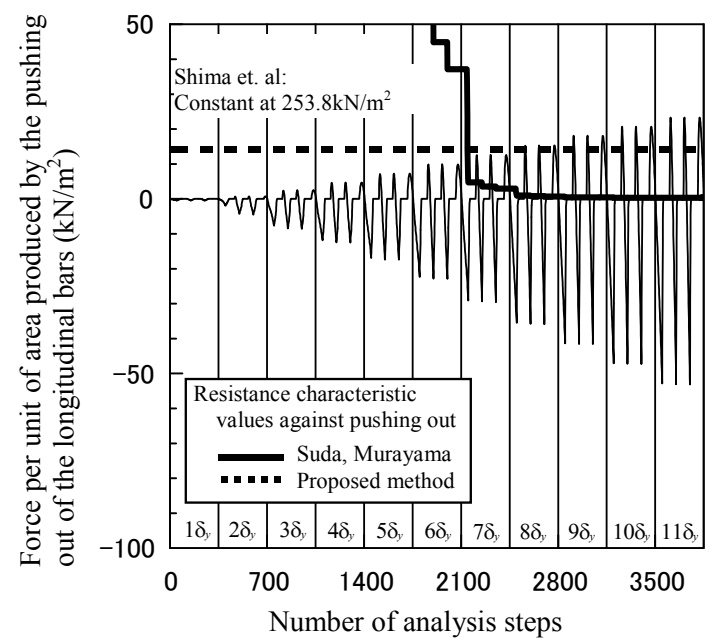

(a) Judgement based on push-out force

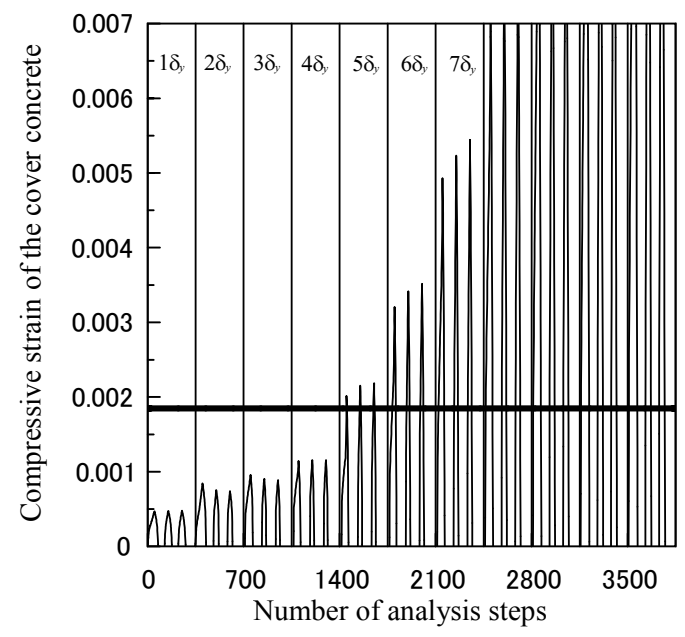

(b) Judgement by compressive strain (Maekawa)

Fig.6 Buckling judgement of longitudinal bars for the S1 specimen

stress-strain curve of the longitudinal bars is not considered, there are great differences between the behavior after buckling.

The most important point of this study is to analytically evaluate what level of deformation of a bridge column must occur before the longitudinal bars start to buckle. So first, the existing assessment method explained in Chapter 2 was used to estimate deformation of the bridge column when its longitudinal bars start to buckle. 
Figs. 4 to 6 show the results of applying the stress in the longitudinal bars obtained by the fiber element analysis and the radius of curvature in the reinforcing bars of the L specimen, S0 specimen, and $\mathrm{S} 1$ specimen respectively to compare the force per unit of area that is produced by the pushing out of cover concrete by the longitudinal bars, and the resistance force per unit of area of the cover concrete based on methods proposed by Suda, Murayama et al. and by Shima et al. And because the assessment method of Maekawa et al. is performed based on the compressive strain generated in the cover concrete, the compressive strain of the cover concrete element on the outermost periphery obtained by fiber element analysis was compared with the strain at time of spalling proposed by Maekawa et al. The force per unit of area pushing out the cover concrete that was produced by the pushing out of the longitudinal bars was calculated by,

$$
\sigma_{H}=\frac{H}{L s_{l}}=\frac{A_{s} \sigma_{s} \phi}{s_{l}}
$$

where,

$\sigma_{H}$ : force per unit of area applied by the longitudinal bars pushing out the cover concrete

$H$ : force of the longitudinal bars pushing out the cover concrete calculated by equation (2)

$L$ : the element division height, here it is the plastic hinge length calculated by the equation of Asazu et al.

$s_{l}$ : net interval of the longitudinal bars

$A_{s}$ : section area of the longitudinal bars

$\sigma_{s}$ : stress generated in the longitudinal bars obtained by the fiber element analysis

$\phi$ : average radius of curvature of the longitudinal bars obtained in the element division height $L$ range; obtained by the equation (4).

$$
\phi=\frac{\theta}{L}
$$

where,

$\theta$. angle of rotation generated in the longitudinal bar element within the plastic hinges obtained by the fiber element analysis (see Fig. 1).

And because the longitudinal bars in S1 specimen are arranged in two layers, it is impossible to directly apply equation (3). Therefore, Fig.6 shows the results of using equation (7) that is described below to calculate the force per unit area by adding the impact of the pushing out of the cover concrete by the interior longitudinal bars.

The resistance force of the cover concrete is first evaluated by the method of Suda, Murayama et al., loading displacement at $5 \delta_{\mathrm{y}}$ for the $\mathrm{L}$ specimen, at $8 \delta_{\mathrm{y}}$ for the $\mathrm{S} 0$ specimen, and at $7 \delta_{\mathrm{y}}$ for the $\mathrm{S} 1$ specimen are estimated as the force of the longitudinal bars pushing out the cover concrete. A comparison of the experimental results shows that in the $\mathrm{L}$ specimen and the S0 specimen, the deformation when the cover concrete spalls is over-estimated, though in the S1 specimen in which part of the longitudinal bars were deliberately installed inside the section to control buckling, it is under-estimated. In this way, the method of Suda, Murayama et al. could not appropriately reflect the buckling confining effects of the layout of the longitudinal bars that were installed in the S1 specimen. This occurred because the resistance force of the cover concrete was modeled simply as the cracking resistance of the cover concrete and the core concrete.

The resistance force of the cover concrete calculated by the method of Shima et al. was evaluated as force greater than the force produced by the pushing out of the longitudinal bars of all of the specimens, so that in the specimens that were studied, the spalling of the cover concrete did not occur until the final loading displacement. This evaluation differed from the experimental results.

If the loading displacement when the cover concrete spalls is judged by the method of Maekawa et al., it is $4 \delta_{y}$ for the $L$ specimen and it is $6 \delta_{y}$ for the S0 specimen, and this conforms with the experimental results. But this result was the reverse of the trend seen in the test results, in that it was judged that the cover concrete would spall at loading displacement of $5 \delta_{\mathrm{y}}$ for the $\mathrm{S} 1$ specimen, and the loading displacement when the cover concrete spalled from the $\mathrm{S} 1$ specimen is larger than that for S0 specimen.

There is an established judgement method that can be used to appropriately judge when the cover concrete will spall in response to the buckling of longitudinal bars on a bridge column with its longitudinal bars installed in one layer at the general covering thickness, but it can be stated that as in the case of the S1 specimen, the buckling control effects in a case where the longitudinal bars are arranged in two layers cannot be appropriately considered by an established judgement method.

\section{PROPOSAL CONCERNING A METHOD OF EVALUATING THE BUCKLING CONTROL EFFECTS OF LONGITUDINAL BARS}

\section{(1) Evaluation of the resistance properties of cover concrete}

As explained above, past methods of evaluating 
cover concrete spalling cannot be appropriately applied to a bridge column with its reinforcement arranged as in the S1 specimen. So based on the structural properties of the S1 specimen and the buckling control mechanism of longitudinal bars, a method of evaluating the resistance properties of cover concrete is studied.

Fig.7 schematically shows the interaction of cover concrete with longitudinal bars with a certain radius of curvature produced by compressive deformation. In this study, the cover concrete on the compressive flange side is modeled as an unreinforced beam with the covering thickness as its section height. The modeled unreinforced beam is assumed to resist the force that pushes out the longitudinal bars. If this is done, the thicker the cover is, the more strongly the resistance to the pushing out by the longitudinal bars can be evaluated and the more realistically the effects of the cover concrete can be represented. This means that the beam that represents the cover concrete is, as shown in Fig.7, modeled as an unreinforced beam with a span with effective length of its lateral confining reinforcement $d$, section width with spacing of lateral confining reinforcement $s$, and section height equal to the net cover thickness of the longitudinal bars $c$.

The following hypotheses have been established concerning the analysis model.

1) The beam end support conditions are simple support.

2) The force caused to act on the beam by the pushing out of the longitudinal bars acts as uniform load.

It is hypothesized that in a case where it is considered that the cover concrete resists the force that the longitudinal bars are pushing out as a beam, behavior is more realistically reproduced by modeling both ends of this beam not as completely simple support, but so that a certain degree of resistance is generated against rotational motion under the effects of the cover concrete on both sides. It is also assumed that the force generated by the pushing out of the longitudinal bars acting on the beam is not simple uniform load, but is a complex load distribution. However, because it is difficult to model these effects precisely, this study avoided making the analysis model too complex and was conducted in the study in relatively simple form as explained above.

Based on these analysis conditions, the load distribution when the bending moment at the center of the space reaches cracking moment is obtained by,

$$
p_{c}=\frac{8 M_{c}}{d^{2}}=\frac{8 W \sigma_{b t}}{d^{2}}
$$

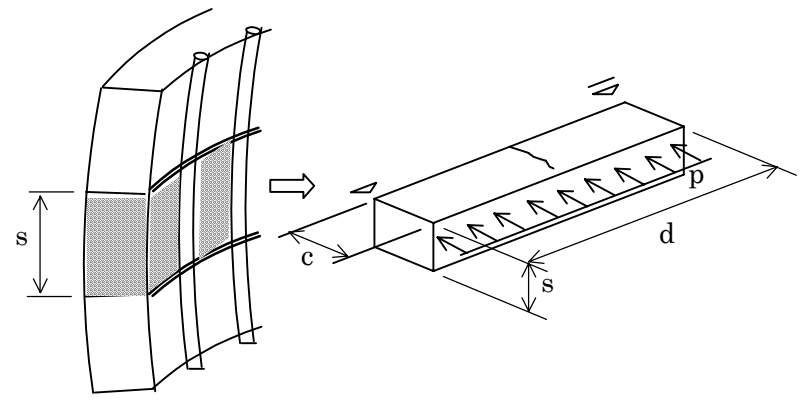

Fig.7 Modeling the force produced by the pushing out of the longitudinal bars and the cover concrete

where,

$p_{c}$ : uniform load caused to act on the beam by the pushing out of the longitudinal bars

$M_{c}$ : cracking moment of the beam

$d$ : effective length of the lateral constraining reinforcement

$W$ : section modulus of the beam $\left(=s \cdot c^{2} / 6\right)$

$\sigma_{b t}$ : bending tensile strength of the cover concrete

$s$ : spacing of the lateral confining reinforcement

$c$ : cover concrete thickness over the longitudinal bars

This means that if equation (5) is divided by the spacing $s$ of the lateral confining reinforcement, the force per unit of area $\sigma_{c r}$ at the time of bending tensile failure of the cover concrete is represented by the equation (6).

$$
\sigma_{c r}=\frac{4}{3}\left(\frac{c}{d}\right)^{2} \sigma_{b t}
$$

Therefore, it is possible to judge that the pushing out of the longitudinal bars will start to spall the cover concrete when the force per unit of area $\sigma_{H}$ applied to the cover concrete by the longitudinal bars obtained by equation (3) exceeds the force per unit of area $\sigma_{c r}$ when the bending tensile failure of the cover concrete occurs as found in equation (6).

\section{(2) Evaluation of the force of the longitudinal bars pushing out the cover concrete in a case where the longitudinal bars were installed in two layers}

Because the longitudinal bars were installed in two layers in the S1 specimen, the force applied to the cover concrete by the interior longitudinal bars must be appropriately modeled. As shown in Fig.8, cover concrete with thickness $c_{2}$ on the interior longitudinal bars resists the force of the interior longitudinal bars pushing out the cover concrete as a beam. And cover concrete with thickness $c_{1}$ resists the exterior longitudinal bars. The evaluation was done by converting the impact of the force applied 


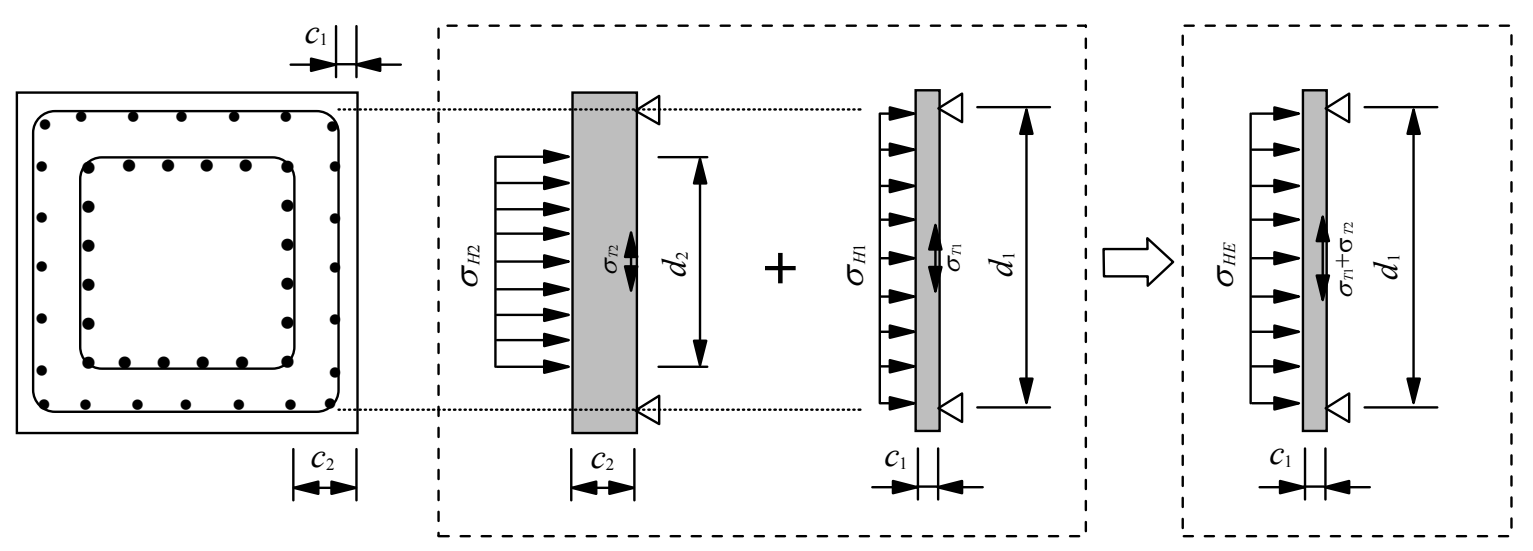

Fig.8 Evaluation of the force of the longitudinal bars pushing out the cover concrete in a case where the longitudinal bars are installed in two layers

by the interior longitudinal bars to the pushing out force of the exterior longitudinal bars. In brief, the force pushing on the cover concrete was corrected so that the tensile stress generated in the section at the center of the space by the pushing out by the interior longitudinal bars of a beam with span length $d_{1}$ and height $c_{2}$ was equal to the stress generated at the tension side of the beam with span length $d_{1}$ and height $c_{1}$, and the force of the longitudinal bars installed in two layers pushing the cover concrete height $c_{1}$ was obtained by,

$$
\sigma_{H E}=\frac{H_{1}}{L s_{l 1}}+\frac{c_{1}^{2}}{c_{2}^{2}} \frac{d_{2}\left(2 d_{1}-d_{2}\right)}{d_{1}^{2}} \frac{H_{2}}{L s_{l 2}}
$$

where,

$\sigma_{H E}$ : equivalent force per unit area of the exterior and the interior longitudinal bars pushing on cover concrete with thickness of $c_{1}$

$H_{1}, H_{2}$ : force of the exterior and interior longitudinal bars pushing on the cover concrete

$L$ : element division height, it is the plastic hinge length calculated by the equation of Asazu et al.

$c_{1}, c_{2}$ : cover thickness on the exterior and interior longitudinal bars

$s_{l 1}, s_{l 2}$ : net interval between the exterior and interior longitudinal bars

$d_{1}, d_{2}$ : effective length of the exterior and interior hoop ties

\section{(3) Comparison with the test results}

The results of the calculation of the force per unit area $\sigma_{c r}$ at the time of bending tensile failure of the cover concrete based on equation (6) for the $\mathrm{L}$ specimen, S0 specimen and the S1 specimen are shown by the wavy lines in Figs. 4 to 6 respectively. The bending tensile strength of the cover concrete was obtained by, ${ }^{1)}$

$$
\sigma_{b t}=0.23 \sigma_{c k}^{2 / 3}
$$

where,

$\sigma_{c k}$ : compressive strength of concrete used to make the test specimens $\left(\mathrm{N} / \mathrm{mm}^{2}\right)$

$\sigma_{H}$ exceeds $\sigma_{c r}$ at loading displacement of $4 \delta_{\mathrm{y}}$ in the $\mathrm{L}$ specimen. This loading step corresponds with experimental results in which the longitudinal bars buckled, spalling the cover concrete. Similarly, this evaluation conforms with test results for the S0 specimen and S1 specimen in which $\sigma_{H}$ or $\sigma_{H E}$ exceeds $\sigma_{c r}$ at loading displacements of $6 \delta_{\mathrm{y}}$ and $8 \delta_{\mathrm{y}}$ respectively.

The longitudinal bar buckling control effectiveness of cover concrete can be evaluated as being in conformity with experimental results by calculating the resistance of the cover concrete and the force applied by the longitudinal bars based on equations (6) and (7).

\section{SUMMARY}

This study proposed an analysis method to estimate the quantity of deformation of a bridge column when its longitudinal bars begin to buckle as they push out the cover concrete based on fiber element analysis, and verified its applicability by comparing it with the results of past cyclic loading test results. The study has revealed the following information.

1) As a result of the verification of the applicability of the proposed methods to evaluate the buckling of longitudinal bars in an RC bridge column subjected to cyclic loading based on test data that includes full-size bridge column tests that the authors performed in the past, it has been confirmed that if the longitudinal bars are installed in one layer and the normal cover thickness is 
applied, it is possible to estimate the deformation of a bridge column when its longitudinal bars buckle, spalling the cover concrete with good precision by the method proposed by Maekawa et al.

2) If the longitudinal bars are installed in two layers, the applicability of the proposed methods to reinforcement arrangement of the S1 specimen that was an object of this study is poor, because it cannot appropriately consider the effects of the interior longitudinal bars.

3) The study proposed a method of evaluating the force pushing out the cover concrete when the longitudinal bars are installed in two layers, and the resistance of the cover concrete to this force. Characteristics of this method are that the cover concrete is considered to be a beam, and the thicker the cover concrete is, the more the resistance of this force pushed out by the longitudinal bars can be overestimated.

4) The study has confirmed that it is possible to accurately estimate the deformation of a bridge column when the longitudinal bars buckle, starting to spall the cover concrete by this proposed method for both the L specimen and S0 specimen with a single layer of reinforcement and the S1 specimen with two layers of reinforcement that were the objects of the study.

ACKNOWLEDGMENT: This study was performed as part of "Research on the improvement of the earthquake disaster prevention performance of the infrastructure based on clarifying the failure process of structures" that is supported by the government's Science and Technology Promotion and Coordination Fund. The Third Team of the Third Subcommittee on "Research on the improvement of the earthquake disaster prevention performance of the infrastructure based on clarifying the failure process of buildings" established by the Organization for Promotion of Civil Engineering Technology JSCE also provided invaluable advice. The authors wish to express their deep gratitude to everyone who assisted them with the performance of this study.

\section{REFERENCES}

1) Japan Road Association: Specifications of Highway Bridges Part V. Seismic Design, March 2002.

2) Railway Technical Research Institute: Model Code for Design of Railway Structures, Seismic Design, October 1999.

3) Japan Society of Civil Engineers, Standard Specifications for Concrete Structures "Seismic Performance Verification", 2002.

4) Suda, K., Murayama, Y., Ichinomiya, T., Shinbo, H.: Experimental Study on Buckling Behaviors of Intermediate Longitudinal Bars in R/C Members, Proceeding of the Japan Concrete Institute, Vol. 16, No. 2, pp. 467 - 452, 1994.

5) Shima, H., Ito, K., Mizuguchi, H.: Ductility Analysis of Flexural Type RC Bridge Piers by Buckling Model of Reinforcement, Proceeding of the Japan Concrete Institute, Vol. 12, No. 2, pp. 741 - 746, 1990.

6) Maekawa, K., Pimanmas, A., and Okamura, H.: Nonlinear Mechanics of Reinforced Concrete, Spon Press.

7) Hoshikuma, J., Unjoh, S., Nagaya, K.: Size Effect on Inelastic Behavior of Reinforced Concrete Column subjected to Cyclic Loading, Journal of the Japan Society of Civil Engineers, No. 669/V-50, pp. 215-232, Feb. 2001.

8) Hoshikuma, J., Unjoh, S., Shiojima, A.: Restraint of Longitudinal Reinforcing Bar Buckling Behavior in RC Columns and Improvement of Flexural Ductility, Fourth Symposium on the Improvement of Seismic Performance Based on the Clarification of Failure Processes of Structures, pp. 215-220, March 2003.

9) Asazu, N., Unjoh, S., Hoshikuma, J., Kondo, M.: Research on Plastic Hinge Length of Reinforced Concrete Columns based on the Buckling Characteristics of Longitudinal Reinforcement, Journal of the Japan Society of Civil Engineers, No. 682/ I-56, pp. 177-194, July 2001.

10) Hoshikuma, J., Kawashima, K., Nagaya, K. and Taylor, A. : Stress-strain Model for Confined Reinforced Concrete in Bridge Piers, Journal of Structural Engineering, Vol.123, No.5, ASCE, 1997.

11) Danilo RISTIC: Nonlinear Behavior and Stress-Strain Based Modeling of Reinforced Concrete Structures under Earthquake Induced Bending and Varying Axial Loads, School of Civil Engineering, Kyoto University, Kyoto, August 1988 .

12) Menegotto, M. and Pinto, P.E.: Method of Analysis for Cyclically Loaded R.C. Plane Frames Including Change in Geometry and Non-elastic Behavior of Elements under Combined Normal Force and Bending, IABSE Symposium on Resistance and Ultimate Deformability of Structures Acted on by Well-defined Repeated Loads, Final Reports, Vol.13, pp.15-22, Lisbon, 1973.

(Received June 1, 2005) 